\title{
Investigation of the effect of Chip Slenderness Ratio and Cutting Tool Approach Angle on Vibration Amplitudes and Chip Morphology
}

\author{
Zülküf Demir $^{1 *}$, Oktay Adryaman ${ }^{2}$ \\ ${ }^{1}$ Mechanical Engineering Department, Faculty of Engineering and Architecture, Batman University, Batman, Turkey, \\ ${ }^{2}$ Mechanical and Manufacturing Engineering Department, Faculty of Technology, Batman University, Batman, Turkey, \\ *zulkuf.demir@batman.edu.tr
}

Received: 3 October 2019

Accepted: 12 December 2019

DOI: $10.18466 /$ cbayarfbe.629157

\begin{abstract}
Machinability, especially turning process, is a significant manufacturing method, but the vibrations, come about the real mechanism of the operation, make difficulties. Unnumbered parameters influence the process outcomes such as machined face raggedness, chip morphology, and vibration amplitudes. In the present research, the effect of tool approaching inclination and chip slenderness ratio (CSR) on the deflection amplitudes, StDev in vibrations, and chip morphology were investigated. For this purpose, $15^{\circ}$, $30^{\circ}$, and $45^{\circ}$ approaching inclinations, $1,3,5,10$, and 15 CSR also depending on CSR values $0,1 \mathrm{~mm} / \mathrm{rev}$, $0,15 \mathrm{~mm} / \mathrm{rev}, 0,45 \mathrm{~mm} / \mathrm{rev}$, and $0,5 \mathrm{~mm} / \mathrm{rev}$ feed rates, $0,5 \mathrm{~mm}, 1 \mathrm{~mm}, 1,5 \mathrm{~mm}$, and 2,25 mm cutting depths were chosen. It was investigated that according to both vibration amplitudes and chip morphology criterion, the most appropriate cutting tool approach angle was $30^{\circ}$, and CSR values were 10 and 15 . Besides, as the cutter approaching inclination progress, the deflection magnitudes in the X (removing deepness) direction were deteriorated, but at small CSR values, they were increased. The optimum feed rates were to be $0,1 \mathrm{~mm} / \mathrm{rev}$ and $0,15 \mathrm{~mm} / \mathrm{rev}$, but the influence of the cutting depth showed differences depending on the values of the selected feed rates. Surface quality was improved at $30^{\circ}$ and $45^{\circ}$ approach angles, $0,1 \mathrm{~mm} / \mathrm{rev}$ and $0,15 \mathrm{~mm} / \mathrm{rev}$ proceeding speeds and 10 and 15 CSR valences. The chips in lamellas form, without sharp deformation breaks and serration generations were perceived at $30^{\circ}$ approaching inclination, $0,1 \mathrm{~mm} / \mathrm{rev}$ and $0,15 \mathrm{~mm} / \mathrm{rev}$ proceeding speeds also at 10 and $15 \mathrm{CSR}$ values.
\end{abstract}

Keywords: Turning, Chip slenderness ratio (CSR), Tool approach angle, Chip morphology, Machinability, Surface roughness, Vibration amplitudes.

\section{Introduction}

Generally, unnumbered selected parameters like the shape of the cutter, characteristics of the metal removed sample and cutter affect the machinability of the metals. The shape of the cutter involves rake, clearance, cutting edge approach angle, and nose radius, whose are influential parameters in machining processes [1]. The tool rake angle, which is an element of the geometry of the cutting tool, has a straight influence on the strain levels in machining [2]. Rake angle provides depreciating the cutting forces also it influences the chip formation. In other words, the serration formation rises, while rake angle changes from negative to positive [3]. Positive rake angles manage minor tensile strain, while negative rake angles, due to triggering the plastic deformation, leading to compressive strain during the machining. Moreover, negative rake angles lead to resulting in poor surface quality and hard tool wear. In other words, the quantity of the plastic and shearing deformations decrease at high selected rake angles [4]. Therefore, the rake angle is a crucial parameter that influential on the remainder and compressive strain [5]. Moreover, as the rake angle rises, the chip fragmentation quantity of the chip serration formation decreases [6]. Furthermore, feed rate, namely tool proceeding speed on the workpiece during metal removing, cutting deepness, and cutting speed are common process parameters in machining. Chip slenderness ratio (CSR), which terms as the ratio of the deepness of removing to the proceeding speed in literature, is a crucial parameter as well. Moreover, CSR is an identifier for the cross-sectional area according to the prolonged shearing speed rule. Depending on CSR the proceeding speed is not advise to be bigger than de cutting depth, also cutting force in machining processes can be attributed to CSR $[1,7]$.

The cutting tool approach angle is the main parameter, affecting the shearing forces, distributing throughout the 
edge of the cutter, due to the dependent movement between the cutter and machined sample, in turning processes. Furthermore, the cutting tool approach angle plays an important role in chip morphology and force magnitude on the edge of the cutter, consequently, insert attrition and its existence [8]. When the shearing forces dispersed on the short part of the edge of the cutter, shearing forces progress, at large cutting edge approaching angles [9].

Chip morphology is a crucial outcome to specify the machinability and surface qualities in machining operations. Therefore, serrating and saw-teethed chips in fragmented formation is a hard problem to solve [10, 11]. At larger selected rake angles, but small feed rates, chips are departed from the machined samples in continuous and helical forms, while they are in short and saw-teethed forms at lower selected rake angles, but larger feed rates [12]. Additionally, chips in short and saw-teethed forms lead to machining endurance [13]. The serration of chip formation, particularly, the pitch dimension of the serrations or saw-teethed, indicated the severity level of the stresses. The serration formation on the removed chips may be able to attribute to the repeated catastrophic shearing instability due to the thermo-plasticity influence. The resulting instability in the shear zone also is an identifier for the vibration level of the operation [14]. Furthermore, the removed bur shape is a crucial outcome to show the magnitude of the vibration amplitude, microwaves, instabilities of multiple shear bands, and chatters, which degrade the surface quality [15]. Moreover, the short, the serration formation and its pitch magnitude show the rigour of the amplitude of the deflection. Scraps are fragmented into tiny parts, in short form due to progressing the crosssectional area, at large proceeding speed, due to the larger cross-sectional areas. Contrarily to the proceeding speed, shear velocity has a small effect on the chip morphology [16].

In metal removing processes, cutting speed, proceeding speed, and deepness of removing are elements, which identify the chip removal rate, especially, the thickness of the removed chip changes depending on the vibration, in the cutting depth direction [17]. Vibrations in machining operations are not desirable due to accelerating insert attrition, consequently causes to mini cutter existence and consequences in great face roughness. With selecting the appropriate metal cutting parameters like feed rate, cutting depth and shear velocity, shape peculiarities of the cutter, connecting procedure, and machined samples, the severity level of vibration, occurring during the process, maybe degraded. Eliminating the vibration in metal cutting operations is not possible due to the mechanism of the process. Vibrations are termed as the deflections of the cutting tool or the machined samples, which results regularly with the proceeding speed, deepness of removing, and shearing velocity, but the influence of the removing deepness on the deflections is little of nothing. Machined face roughness or surface quality is a significant outcome that specifying the grade of the metal cutting, reciprocally related with the proceeding speed $[18,19,20]$. Although the vibrations in machining operations are hard problems to solve with the help of a fastening passive or active dampers on the cutter chuck, the resolution of the operation can substantially develop [21]. Moreover, vibration, especially self-excited deflection denominated as prattle, is a physical characteristic, which causes to the poor face grade and mini cutter existence in the form of catastrophically effect [22]. Moreover, the periodical remainder strains determine the vibration frequency of the tool also the topographic image of the machined surface can be interrelated to the frequency of the cutter vibration [20].

The base purpose of the present research is to explain the effect of feed rate, removing deepness, CSR, which terms in literature as the ratio of removing deepness to the proceeding speed, and the edge of the cutter approaching inclination on the surface roughness, vibration amplitude, StDev in vibration, and chip morphology, in orthogonal machining of AISI 1050 manufacture steel, realized by using a lathe machine.

\section{Materials and Methods}

Tests were put into practise with the help of a SMARC CAK6166B X 2000 CNC model lathe, as demonstrated in Figure (1). A NI-9230 C series model accelerometer was employed to measure the vibration amplitudes between $-30 \mathrm{~g}$, and $+30 \mathrm{~g}$. The vibration amplitude values were recorded on the computer with the help of a data logger and fibre-optic cable. The detector of the accelerometer was attached to the cutter chuck, with using a plaster. Moreover, the cutter chuck, the chuck of the CNC lathe, the processed face of the sample, and cutter were displayed. The directions on the accelerometer's sensor reveal $\mathrm{X}, \mathrm{Y}, \mathrm{Z}$ coordinates of a lathe machine, as demonstrated in Figure (1).

AISI 1050 steel was chosen as samples in dimensions of Ø $30 \mathrm{~mm}$ in diameter and $150 \mathrm{~mm}$ in dimension. In Table 1 and Table 2, the elemental combination and mechanical characteristics of AISI 1050 steel are demonstrated, separately. From the top of the sample to the chuck of the turning machine, each sample was machined $80 \mathrm{~mm}$ in length. Three types of approaching angles of cutters were chosen as $15^{\circ}, 30^{\circ}$, and $45^{\circ}$. Moreover, all tests were realized at $75 \mathrm{rpm}$ constant shearing velocity. However, proceeding speed (f) and deepness of removing (a) were selected according to CSR (a/f) values. CSR values were adjusted to be between 1 and 15, depending on the selected feed rates and the cutting depths. 


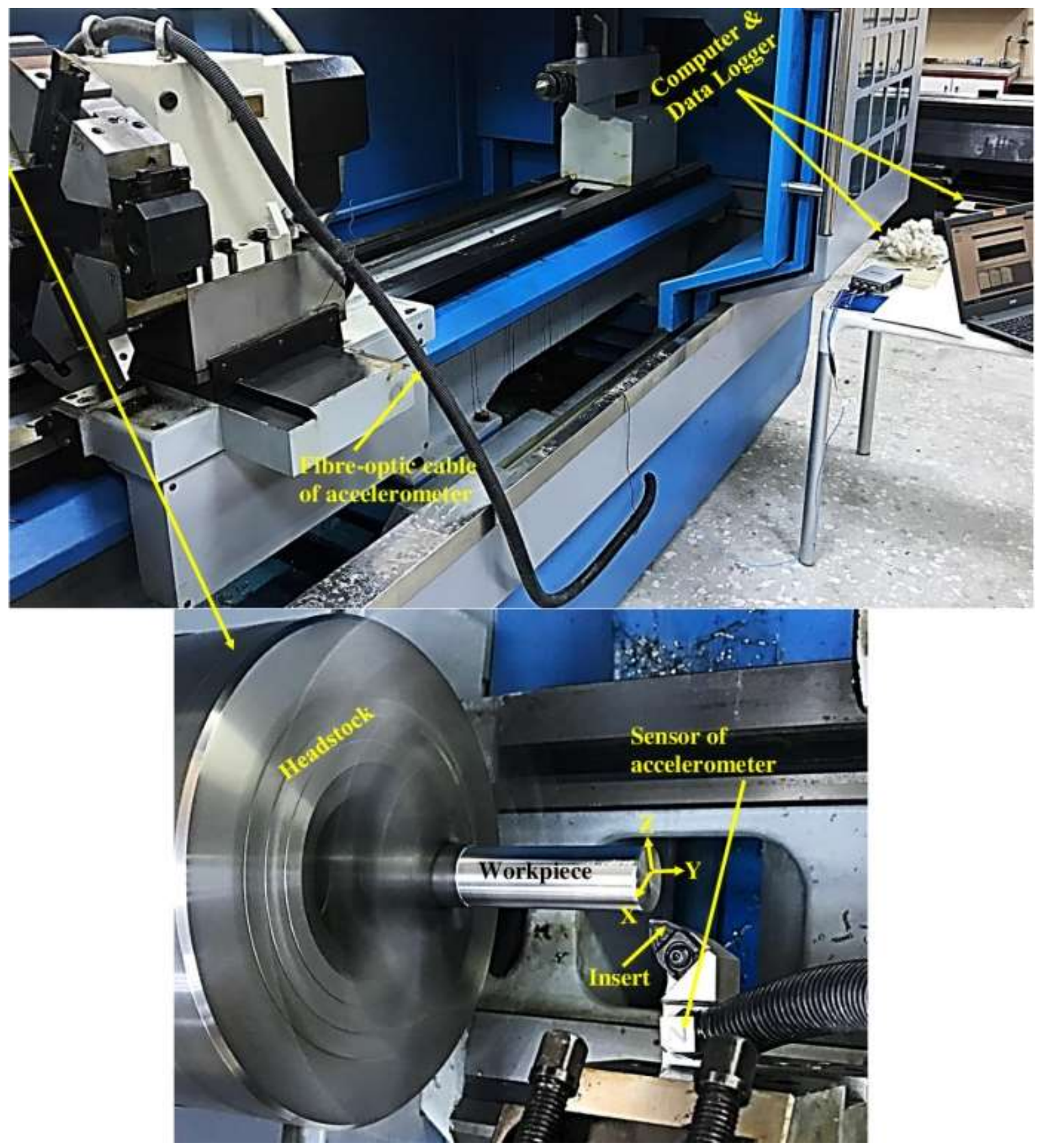

Figure 1. Experimental setup, sensor of accelerometer, computer.

Table 1. Elemental combination of the samples.

\begin{tabular}{cccccc}
\hline Elements & C & Mn & Fe & S & P \\
\hline Weight \% & $\begin{array}{c}0.47- \\
0.55\end{array}$ & $\begin{array}{c}0.60- \\
0.90\end{array}$ & $\begin{array}{c}98.46- \\
98.92\end{array}$ & $\leq 0.05$ & $\leq 0.05$ \\
\hline
\end{tabular}

Three varieties of inserts and tool holders were employed in experiments in the experiment procedure, as regards the tool cutting edge approaching angle criterion. For inserts, $0.8 \mathrm{~mm}$ nose radius, $6^{\circ}$ rake and $8^{\circ}$ relief inclinations in a triangle and square forms were selected. However, tool holders were selected with $15^{\circ}$, $30^{\circ}$, and $45^{\circ}$ approach angles. Inserts in triangle shape have $30^{\circ}$ approach angle, but square ones with $15^{\circ}$ and $45^{\circ}$. 
The morphology of removed chips was analyzed by metallographic studies. For this purpose, an FEI QUANTA 250 FEG scanning electron microscope (SEM) was employed. The machined face raggedness of the removed specimen was evaluated at a sample distribution dimension of $0.8 \mathrm{~mm}$ via a TIME TR 200 transportable appliance.

Table 2. Strength characteristics of the selected samples.

\begin{tabular}{ll}
\hline $\begin{array}{l}\text { Mechanical } \\
\text { Properties }\end{array}$ & Magnitude \& Unit \\
\hline $\begin{array}{l}\text { Strain Resistance } \\
\text { Tensile Resistance }\end{array}$ & $690 \mathrm{MPa}$ \\
$\begin{array}{l}\text { Shearing Modulus } \\
\text { Young's Modulus }\end{array}$ & $80 \mathrm{GPa}$ \\
$\begin{array}{l}\text { Proportion of Poisson } \\
\text { Prolongation of at }\end{array}$ & $0.27-0.30$ \\
crack (in 50 mm) & $0.27-0.30$ \\
Hardness, Brinell & 197 \\
Thermic Conduction & $49.8 \mathrm{~W} / \mathrm{mK}$ \\
\hline
\end{tabular}

\section{Results and Discussion}

3.1. The Impression of CSR on Vibration Amplitudes, StDev in Vibration, and Chip Morphology

Completely elimination of the vibration amplitudes in metal cutting operations is impossible. However, selecting the optimum machining parameters such as proceeding speed, removing deepness, shearing velocity, and pairs of cutter and workpiece, the negative impact of the vibration on the machining operation may be depreciated. Conformably to the vibration amplitudes, the standard deviation in vibration is also an advantageous outcome for identifying the degree of the machinability. Furthermore, chip morphology is a significant identifier for the machinability in metal cutting operations due to it is an indicator for shearing and plastic deformations. The effect of CSR on vibration amplitudes, StDev in vibration, and chip morphology was demonstrated in Figure (2). Figures (2) (a, b, and c, d; e, and f; g, h, and 1) show the impression of CSR on vibration amplitudes, StDev in vibration, and chip morphology depending on the tool approach angle of $15^{\circ}, 30^{\circ}$, and $45^{\circ}$, respectively. Furthermore, Figure (2) (a, d, and g; b, e, and h; c, f, and 1) reveal the influence of CSR on vibration amplitudes, StDev in vibration, and chip morphology, individually. As seen in Figure $(2 \mathrm{a})$, generally, greatest deflection sizes were written down in $\mathrm{X}$ (removing deepness) direction due to CSR is denominated as the proportion of removing deepness to the proceeding speed also cutting depth is more influential on the CSR at $15^{\circ}$ tool approach angle. However, at 15 CSR value, the vibration amplitude in $\mathrm{Z}$ direction was greater than the vibration amplitudes in both $\mathrm{X}$ and $\mathrm{Y}$ directions. Both maximum vibration amplitudes and StDev in vibrations were recorded at 5 and $15 \mathrm{CSR}$ values while minimum ones were at 1, 5, and $10 \mathrm{CSR}$ values. The alteration graphs curves of StDev in vibration show the similarity with graphs curves of the vibration amplitudes, but the values StDev in vibration were smaller than the vibration amplitudes. At 5 CSR value, when small values were selected for cutting depth and feed rates, both vibration amplitudes and StDev in vibration raised regularly, but at large both cutting depth and feed rates vice versa. According to the curves of the graph in Figure ( 2 a and b), the optimum proceeding speed and removing deepness were 0,1 $\mathrm{mm} / \mathrm{rev}$ and $1 \mathrm{~mm}$, individually. Although at 0,5 $\mathrm{mm} / \mathrm{rev}$ proceeding speed and $0,5 \mathrm{~mm}$ cutting deepness the vibration amplitudes and StDev in vibration were in proper values they were not taken into account due to the small cutting depth value, which was tinier than the nose radius $(0,8 \mathrm{~mm})$. Therefore, the small values in vibrations were attributed to the material plastered on the face of the machined sample by cutter. As seen in Figure $(2 \mathrm{c})$, as convergence the values of the proceeding speed and removing deepness the deformation crevices, serration formation with great pitch dimension, were progressed regularly. Therefore, the optimum chip formation, in lamella form, without deformation cracks, and serration with large pitch sizes were achieved at $15 \mathrm{CSR}, 0,45 \mathrm{~mm} / \mathrm{rev}$ feed rate, 2,25 $\mathrm{mm}$ removing deepness, and at $15^{\circ}$ approach angle. Although the proceeding speed and removing deepness increase contrarily to vibration amplitudes and StDev in deflection, chip morphology was improved.

Figure ( $2 \mathrm{~d}$, e, and f) show the vibration amplitudes, StDev in vibration and chip morphology, respectively, for 30o tool approach angle. When tool approach angle change from $15^{\circ}$ to $30^{\circ}$ the maximum vibration amplitudes and StDev in vibrations in $\mathrm{Z}$ direction were recorded to be tinier than in the $\mathrm{X}$ and $\mathrm{Y}$ strikes. Contrary to $15^{\circ}$ approaching angle, at $30^{\circ}$ approaching angle, the smallest vibration amplitudes and StDev in vibrations were achieved in the $\mathrm{X}$ (removing deepness) strike, which was pursued by Y (cutter progressing) and $\mathrm{Z}$ strikes, respectively. According to Figure ( $2 \mathrm{~d}$ and e), as increases in tool approach angle, the negative influence of cutting depth on both vibration amplitudes and StDev in vibrations was diminished. However, as similar at $15^{\circ}$ approach angle, the maximum vibration amplitudes and $\mathrm{StDev}$ in vibrations were recorded at 3 , 5, and 15 CSR while the smallest ones at 1, 5, and 10 CSR values. As seen in Figure (2 f), at 1, 3, and 5 CSR assets, severe deformation crevices, saw-teeth shaping with large lead dimension were observed, but at 5, 10, and 15 CSR values the serration formation gave its place to lamellas formation, on which micro-cracks, without serration, observed. Two kinds of 5 CSR values were taken into account relying on the selected different removing deepness and proceeding speed. At CSR, for 
which $0,1 \mathrm{~mm} / \mathrm{rev}$ proceeding speed and $0,5 \mathrm{~mm}$ removing deepness were selected, lamellas formation, without serration and deformation cracks, were observed, but at $0,45 \mathrm{~mm} / \mathrm{rev}$ proceeding speed and 2,25 $\mathrm{mm}$ removing deepness, violent deformation crevices and saw-teeth shaping was displayed.

As demonstrated in Figure ( $2 \mathrm{~g}$ and $\mathrm{h})$, as a tool approach angle adjustment to $45^{\circ}$, in general, vibration amplitudes and StDev in vibrations were decreased. As similar to $15^{\circ}$ tool approach angle, at $45^{\circ}$, maximum vibration amplitudes and StDev in vibrations were observed in the $X$ (removing deepness) strike, which was pursued by $\mathrm{Y}$ (cutter progressing) and $\mathrm{Z}$ strikes, individually. At $45^{\circ}$ approaching angle, optimum CSR values were to be between 5 and 10, according to the vibration amplitudes and StDev in vibrations criterion. Figure $\left(\begin{array}{l}2 \\ 1\end{array}\right)$ shows chip morphology, which achieved at $45^{\circ}$ approaching angle. The deformation crevices and saw-teeth shaping having large pitch sizes were seen at 3 and 5 CSR assets also at high selected feed rates and cutting depths. However, at small feed rates and cutting depths, violent deformation crevices and saw-teeth shaping gave its place to lamellas shaping with tiny crevices and serration formation with small pitch sizes. Therefore, a smoother surface was observed at 15 CSR and $45^{\circ}$ cutter approaching angle. The smooth chip surface formation without cracks and serration is ascribed to greatest cutting strength obtained at $45^{\circ}$ slope angle.
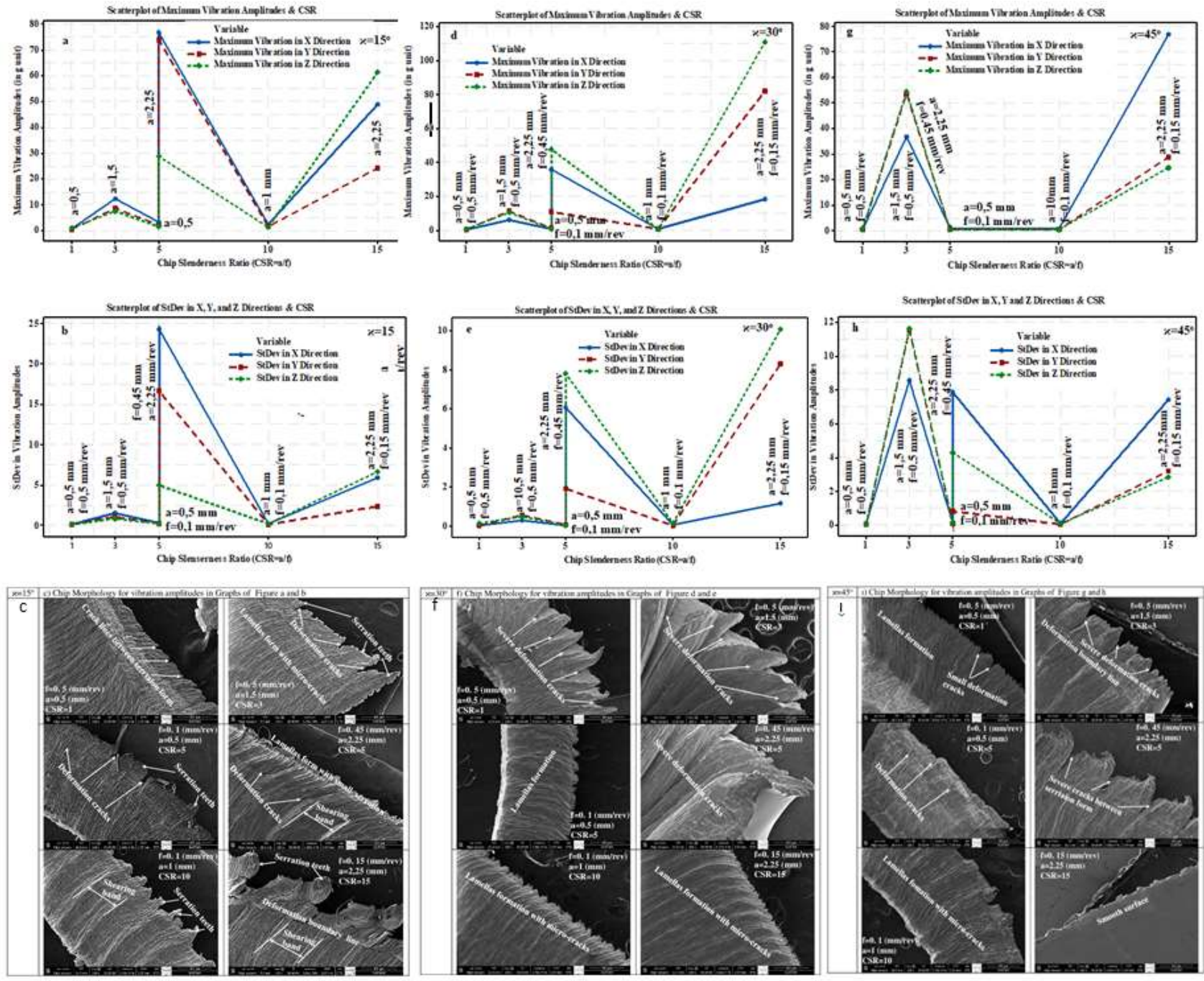

Figure 2. The effect of CSR on maximum vibration amplitudes in $\mathrm{X}, \mathrm{Y}$, and $\mathrm{Z}$ directions \& StDev in vibration amplitudes \& chip morphology at, a, b, and c) $15^{\circ}$; d, e, and f) $30^{\circ}$; g, h, and 1) $45^{\circ}$ approach angles. 


\subsection{The Influence of CSR on Surface Roughness}

Machined face raggedness is a significant outcome, which taken into account in machining operations, identifying the machinability degree. Naturally, the most influential parameter on machined face raggedness is the proceeding speed. Therefore, as displayed in Figure (3), maximum surface raggedness assets were obtained in $\mathrm{Y}$ (tool proceeding) direction, which was followed by $\mathrm{Z}$ and $\mathrm{X}$ directions, individually, at CSR values smaller than 10 . However, at CSR values 10 and higher, surface roughness values were diminished regularly. Moreover, the minimum surface roughness values were recorded in $\mathrm{Y}$ (tool proceeding) direction. Furthermore, as the feed rate increased machined face raggedness progressed. Wherefore, the optimum surface quality was seen at $0,1 \mathrm{~mm} / \mathrm{rev}$ and $0,15 \mathrm{~mm} / \mathrm{rev}$ proceeding speeds.

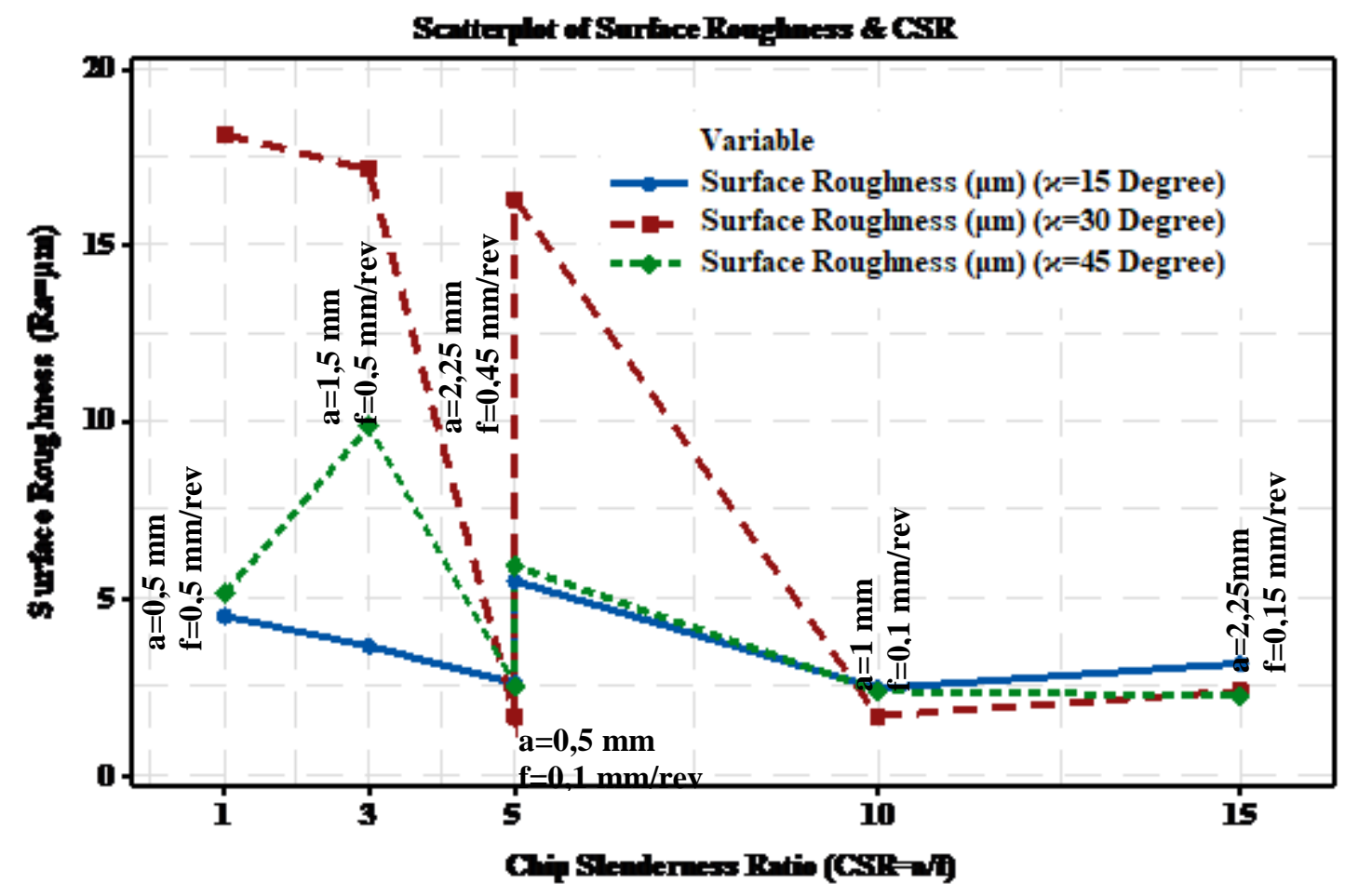

Figure 3. The impression of CSR over the machined face raggedness.

\subsection{The Impression of Tool Approach Inclination on Vibration Amplitudes, StDev in Vibration, and Chip Morphology}

Cutting tool approach angle is one of the most influential parameters in machining operations due to the greatest cutting resistance taken place at $45^{\circ}$ approaching inclination. Figures (4 a, c, e, g, 1, and k) show the influence of tool approaching inclination on the maximum deflection amplitudes and removed bur shape while Figures ( $4 \mathrm{~b}, \mathrm{~d}, \mathrm{f}, \mathrm{h}, \mathrm{j}$, and l) show the StDev in vibration and the alteration graphs of the recorded vibration amplitudes with the help of NI-9230 $\mathrm{C}$ series model accelerometer. As increases tool approaching angle from $15^{\circ}$ to $45^{\circ}$ vibration amplitudes were decreased regularly, as seen in Figure (4 a). Moreover, the cracks and serration formation took its place to lamellas formation. At 1 CSR value, minimum vibration amplitudes were observed in the $\mathrm{Y}$ direction, pursued by $\mathrm{X}$ and $\mathrm{Z}$ stakes, separately. However, as displayed in Figure (4 b), maximum StDev in vibration values were observed in the $\mathrm{Z}$ direction. Additionally, the alteration in Figure ( $4 \mathrm{a}$ and $\mathrm{b}$ ) demonstrate the similarity routes. When CSR value increases to 3 , both the vibration amplitudes and StDev in vibrations were progressed linearly, as tool approach angle change from $15^{\circ}$ to $45^{\circ}$, as displayed in Figure (4 c and d). Moreover, the deformation cracks and chip serration increased as well. As the CSR values increased to 3, the minimum vibration amplitudes and StDev in vibrations were recorded at approach angles $30 \mathrm{o}$ and smaller.

Figures (4 e, f, g, and h) show the impression of the tool approaching angle on the vibration amplitudes, $\mathrm{StDev}$ in vibration, and chip morphology, at 5 CSR value, but at different proceeding speeds and removing deepness. Although diverse proceeding speeds and removing deepness were selected, the changing routes of curves of the influence of approaching angle on both vibration amplitudes and StDev in vibration showed the similarity, at $5 \mathrm{CSR}$ value. However, at $0,45 \mathrm{~mm} / \mathrm{rev}$ proceeding speed and $2,25 \mathrm{~mm}$ removing deepness, the recorded vibration amplitudes and StDev in vibrations were rather larger than the values obtained at 0,1 $\mathrm{mm} / \mathrm{rev}$ feed rate and $0,5 \mathrm{~mm}$ removing deepness. Chip formation occurred depending on the feed rates and 
cutting depths. At greater proceeding speeds and removing deepness, chips with violent deformation breakages and saw-teeth were seen while at small feed rates and cutting depths, chips were in lamellas form with micro-cracks, but without serration. Additionally, chip morphology and vibration amplitudes were not demonstrated compatibleness depending on CSR and approach angle values.
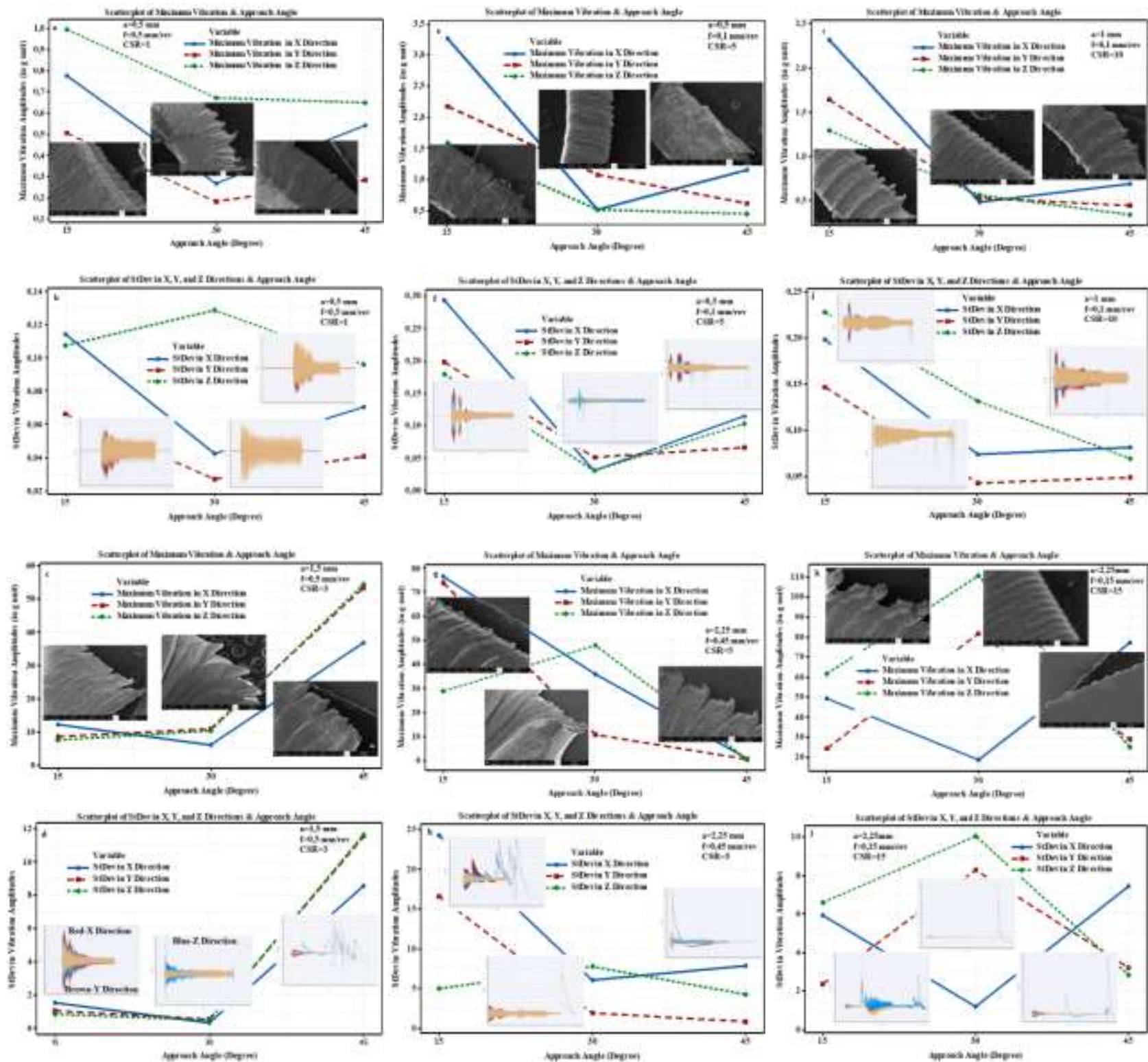

Figure 4. The impression inclination on deflection magnitudes \& StDev in vibration at, a, b) $C S R=1$; c, d) $C S R=3$; e, f) $C S R=5$; g, h) $C S R=5 ; 1, j) C S R=10 ; k$, l) $C S R=15$

In Figures (4 1, j, k, and 1), the impact of the approaching angle on the vibration amplitudes, StDev in vibrations, and chip morphology were demonstrated, at 10 and $15 \mathrm{CSR}$ values. At $10 \mathrm{CSR}$ value, with increasing tool approach angle, the vibration amplitudes were decreased linearly. Therefore, the minimum vibration amplitudes and StDev in vibration values were recorded at $30^{\circ}$ and bigger approach angles, as seen in Figures (4 1, and j). Cracks and serration formation become lost at approaching angle increased linearly, especially, at 30o. However, at $15 \mathrm{CSR}$ value, vibration amplitudes were increased in $\mathrm{Y}$ and $\mathrm{Z}$ directions linearly depending on approaching angle, but the smallest vibration amplitude values were recorded at $30^{\circ}$ approach angle, as seen in Figure (4 $\mathrm{k}$ and 1$)$. Additionally, the desired chip formation, according to the machinability criterion, was observed at $30^{\circ}$ approaching inclination and $15 \mathrm{CSR}$ values. 
Celal Bayar University Journal of Science

Volume 15, Issue 4, 2019 p xxx-Xxx

\subsection{The Influence of Tool Approach Angle on Machined Face Raggedness}

The effect of cutting cutter approaching inclination on the machined face roughness was demonstrated in Figure (5). Figure (5 a) demonstrates the impression of the approaching inclination for all selected CSR values, feed rates, and cutting depths. In the experiment procedure, two kinds of 5 CSR values were chosen with changing the feed rates and cutting depths. One of 5 CSR value was obtained at $0,1 \mathrm{~mm} / \mathrm{rev}$ proceeding speed and $0,5 \mathrm{~mm}$ removing deepness while the second was at $0,45 \mathrm{~mm} / \mathrm{rev}$ proceeding speed and $2,25 \mathrm{~mm}$ removing depth. Therefore, Figures ( $5 \mathrm{~b}$ and c) Show the effect of approach angle on surface roughness at 1 , 3,10 , and 15 also include two different kinds of 5 CSR values, but the first $5 \mathrm{CSR}$ value (only at $0,1 \mathrm{~mm} / \mathrm{rev}$ proceeding speed and $0,5 \mathrm{~mm}$ removing deepness) and the second 5 CSR (only at $0,45 \mathrm{~mm} / \mathrm{rev}$ feed rate and

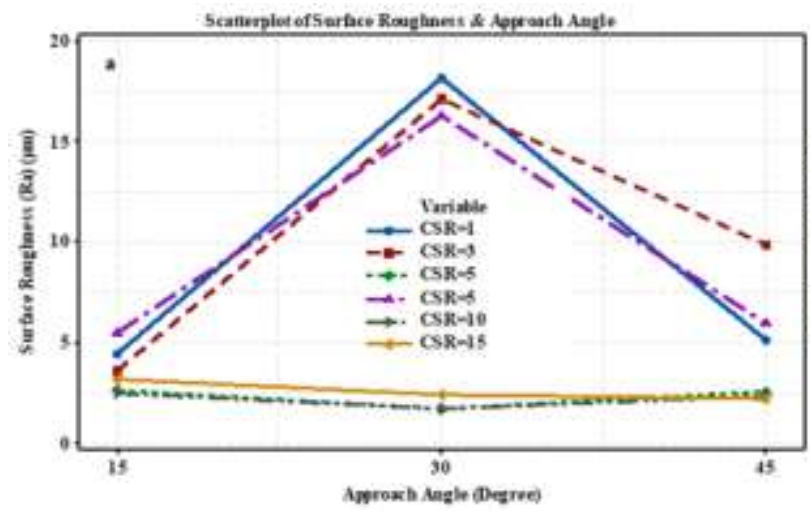

2,25 $\mathrm{mm}$ removing deepness), respectively. As seen in Figure (5 a), at 10 and 15 CSR values, the minimum machined face raggedness assets were recorded while at 1 and 3 CSR values the poor surface quality was achieved. At $0,1 \mathrm{~mm} / \mathrm{rev}$ proceeding speed even at 5 CSR value, the surface quality improved regularly, as demonstrated in Figure $(5 \mathrm{~b})$, but at $0,45 \mathrm{~mm} / \mathrm{rev}$ feed rate and $2,25 \mathrm{~mm}$ removing deepness, at $5 \mathrm{CSR}$ value the surface roughness values progressed severely, as in Figure $(5 \mathrm{c})$. According to the surface criterion, at CSR values 5 and bigger, surface quality improved, but at 5 CSR and smaller, the surface roughness values were increased regularly. Additionally, the highest surface roughness assets were obtained at $30^{\circ}$ approach angle at smaller CSR values. However, at higher CSR values with rising tool approach inclination, surface quality was improved regularly. As the proceeding speed increased, the surface roughness was naturally increased.
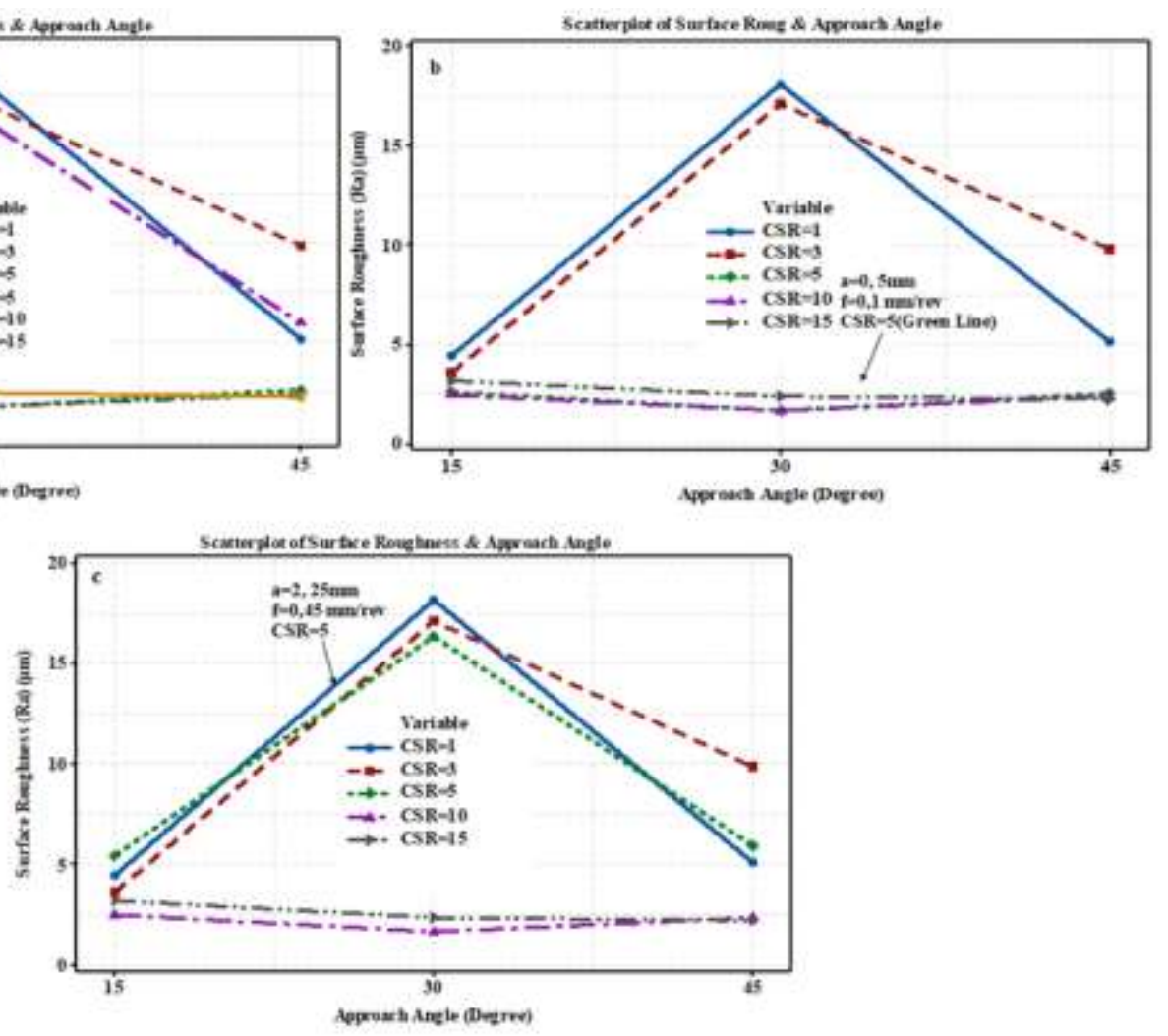

Figure 5. The impression of approaching inclination on surface roughness a) at all of selected parameters, b) including only $\mathrm{CSR}=5$ for $\mathrm{f}=0,1 \mathrm{~mm} / \mathrm{rev}, \mathrm{a}=0,5 \mathrm{~mm}, \mathrm{c}$ ) including only $\mathrm{CSR}=5 \mathrm{for} \mathrm{f}=0,45 \mathrm{~mm} / \mathrm{rev}, \mathrm{a}=2,25 \mathrm{~mm}$.

\section{Conclusion}

Vibration amplitudes, the StDev in vibration and chip morphology were investigated at different cutting tool approach angles, CSR, accordingly, feed rates and cutting depths, in machining of AISI 1050 steel via a lathe machine. The common results obtained from the experimental investigation are listed below.
- At high CSR, proceeding speed and removing deepness values, the amplitude of the vibration and the deformation cracks in the chip morphology increased.

- The tiniest deflection amplitude assets were obtained at $30^{\circ}$ cutting-tool approaching inclination. According to the vibration criterion, the most appropriate approach angle was found to be $30^{\circ}$. 
- The change in chip morphology and vibration amplitude were not shown compatibleness. Thus, the optimal chip morphology was achieved at 15 CSR $(0.15 \mathrm{~mm} / \mathrm{rev}$ proceeding speed and $2.25 \mathrm{~mm}$ removing depth).

- It was found that the proceeding speed and removing depth were more effectual parameters on vibration amplitude than CSR. However, both CSR and cutter approaching inclination had a regular impact on-chip morphology.

- It has been found that the furthest efficient parameter on the machined face raggedness is the proceeding speed. Besides, better quality surfaces were obtained at CSR values of 5 and higher.

- As the cutting tool approach angle increases, the vibration amplitude regularly reduces at small CSR values.

- According to both chip morphology and vibration amplitude criterion, the most appropriate tool approach angle was 30o, CSR values were 10 and 15 , feed rates were $0.1 \mathrm{~mm} / \mathrm{rev}$ and $0.15 \mathrm{~mm} / \mathrm{rev}$, but the influence of cutting depth demonstrated diverges relying on the feed rate.

- The smallest vibration amplitudes were recorded at 15 CSR and $30^{\circ}$ tool approach angles in the X (cutting depth) direction. However, in small CSR and tool approach angles, the vibration amplitudes in the $\mathrm{X}$ direction, deformation cracks and serration formation on the chip morphology progressed.

- As the distinction between removing deepness and feed rate, namely the CSR value, increased the machinability also developed.

\section{Ethics:}

There are no moral problems after the writing of this script.

\section{References}

1. Kronenberg, M. Machining science and application theory and practice for operation and development of machining processes Arrowsmit Ltd. UK, 1996; pp 170-182.

2. Cui, X, Guo, J. 2017. Effects of cutting parameters on too temperatures in intermittent turning with the formation of serrated chip considered. Applied Thermal Engineering; 110: 1220-1229.

3. Duan, C, Dou, T, Wang M. 2009. Experimental Research of chip formation mechanism during high speed machining of hardened steel International Journal of Advanced Engineering Applications (IJAEA) 2(3): 17-21.

4. Liu, HZ, Wang, SJ, Zong, WJ. 2019. Tool rake angle selection in micro-machining of $45 \mathrm{vol} . \% \mathrm{SiCp} / 2004 \mathrm{Al}$ based on its brittle-plastic properties. Journal of Manufacturing Processes; 37: 556-562.

5. Dahlman, P, Gunnberg, F, Jacobson, M. 2004. The influence of rake angle, cutting feed and cutting depth on residual stresses in hard turning. Journal of Materials Technology; 147: 81-184.

6. Atlati, S, Haddag, B, Nouari, M, Zenasni, M. 2011. Analysis of a new segmentation intensity ratio "SIR" to characterize the chip segmentation process in machining ductile metals. International Journal of Machine Tools \& Manufacture; 51: 687-700.
7. Liu, R, Eaton, E, Yu, M, Kuang, J. 2017. An investigation of side flow during chip formation in orthogonal cutting. Procedia Manufacturing; 10: 568-577.

8. Sun, Z, Shuang, F, Ma, W. 2018. Investigations of vibration cutting mechanisms of Ti6Al4V alloy. International Journal of Mechanical Sciences; 48: 510-530.

9. Su, G, Liu, Z, Li, L, Wang, B. 2015. Influences of chip serration on micro-topography of machined surface in high-speed cutting. International Journal of Machine Tools \& Manufacture; 89: 202-207.

10. Ducobi, F, Lorphevre, ER, Filippi, E. 2016. Materials constitutive model and chip separation criterion influence on the modeling of Ti6Al4V machining with experimental validation in strictly orthogonal cutting condition. International Journal of Mechanical Sciences; 107: 136-149.

11. Ahearne, E, Baron, S. 2017. Fundamental mechanisms in orthogonal cutting of medical grade cobalt chromium alloy (ASTM F75). CIRP Journal of Manufacturing Science and Technology; 19: 1-

12. Astakhov, VP, Shvets, S. 2003. The assessment of plastic deformation in metal cutting. Journal of Materials Processing Technology; 146: 193-202.

13. Zhang, SJ, To, S, Wang, SJ, Zhu, ZW. 2015. A review of surface roughness generation in ultra-precision machining. International Journal of Machine Tools \& Manufacture; 91: 76-95.

14. Das, D, Sahoo, BP, Bansal, S, Mishra, P. 2018. Experimental investigation on material removal rate and chip forms during T6 tempered Al 7075 alloy. Materials Today: Proceedings; 5 (2): 32503256

15. Munoa, J, Beudaert, X, Erkorkmaz, K, Iglesias, A. 2015. Barrios, A, Active suppression of structural chatter vibrations using machine drives and accelerometers. CIRP Annals-Manufacturing Technology; 64: $385-388$.

16. Ramanaiah, BV, Manikanta, B, Sankar, MR, Malhotra, M, Gajrani, KK. 2018. Experimental study of deflection and surface roughness in thin wall machining of aluminium alloy. Materials Today: Proceedings; 5 (2): 3745-3754

17. Palacios, J. A, Olvera, D, Urbikain, G, Zuniga, A. E, Romero, O. M, Lacalle, LNL, Rodriguez. C, Alfaro, HM. 2018. Combination of simulated annealing and pseudo spectral methods for the optimum removal rate in turning operations of nickel-based alloys. Advances in Engineering Software; 115: 391-397.

18. Thamizhmanii, S, Hasan, S. 2012. Machinability study using chip thickness ratio on difficult to cut metals by $\mathrm{CBN}$ cutting tool. Key Engineering Materials; 504-506: 1317-1322.

19. Silva, LR, Abra, AM, Faria, P, Davim, JP. 2012. Machinability study of steels in precision orthogonal cutting. Materials Research 15(4): 589-595.

20. Bordin, A, Bruschi, S, Ghiotti, A. 2014. The effect of cutting speed and feed rate on the surface integrity in dry turning of CoCrMo alloy. Procedia CIRP; 13: 219-224.

21. Nesluŝan, M, Sípek, M, Mrázik, J. 2012. Analysis of chip formation during hard turning through acoustic emission. Materials Engineering-Materiálové inžierstvo; 19: 1-11.

22. Yan, L, Zhang, Q, Yu, J. 2018. Analytical models for oil penetration and experimental study on vibration assisted machining with minimum quantity lubrication. International Journal of Mechanical Sciences; 148: 374-382. 